See Article page 134.

\section{Commentary: Virtual reality in presurgical planning: The future is already here}

\author{
Kanwal M. Farooqi, MD, and \\ David Kalfa, MD, $\mathrm{PhD}^{\mathrm{b}}$
}

The study by Davies and colleagues ${ }^{1}$ in this issue of the Journal highlights the utility of virtual reality (VR) in the presurgical assessment of implantation of adult-sized ventricular assist device (VAD) in pediatric patients. The authors demonstrate the application of this innovative technology for intrapericardial placement of the Heartware HVAD and Heartmate 3 in 3 patients with body surface area ranging from 0.65 to $0.67 \mathrm{~m}^{2}$.

Given the benefit of VAD support in improving end organ function and post-heart transplantation mortality, ${ }^{2,3}$ preprocedural planning for device placement should be optimized using innovative imaging modalities as described in this report. Variations in ventricular morphology, trabeculations of a systemic right ventricle that can obstruct the inflow cannula, and abnormal arterial spatial anatomy all add a level of complexity to VAD placement in patients with congenital heart disease. Unconventional technologies, such as VR, should be used in such challenging cases. The representation of the chest wall and cardiac mass in true 3 dimensions using VR enables assessment of the atrioventricular valve inflow and virtual alignment of the VAD inflow cannula. The authors were able to identify 1 patient in whom the position of the inflow cannula would have been in close proximity to the

From the ${ }^{\mathrm{a}}$ Division of Pediatric Cardiology, Department of Pediatrics and ${ }^{\mathrm{b}}$ Section of Pediatric and Congenital Cardiac Surgery, Division of Cardiac, Thoracic, and Vascular Surgery, New York Presbyterian-Morgan Stanley Children's Hospital, Columbia University Medical Center, New York, NY.

Disclosures: The authors reported no conflicts of interest.

The Journal policy requires editors and reviewers to disclose conflicts of interest and to decline handling or reviewing manuscripts for which they may have a conflict of interest. The editors and reviewers of this article have no conflicts of interest.

Received for publication Dec 5, 2020; revisions received Dec 5, 2020; accepted for publication Dec 18, 2020; available ahead of print Dec 25, 2020.

Address for reprints: David Kalfa, MD, PhD, Pediatric Cardiac Surgery, New York Presbyterian-Morgan Stanley Children's Hospital, Columbia University Medical Center, 3959 Broadway, CHN-274, New York, NY 10032 (E-mail: dk2757@ cumc.columbia.edu).

JTCVS Techniques 2021;6:138-9

2666-2507

Copyright $(2020$ The Authors. Published by Elsevier Inc. on behalf of The American Association for Thoracic Surgery. This is an open access article under the CC BY-NCND license (http://creativecommons.org/licenses/by-nc-nd/4.0/).

https://doi.org/10.1016/j.xjtc.2020.12.008

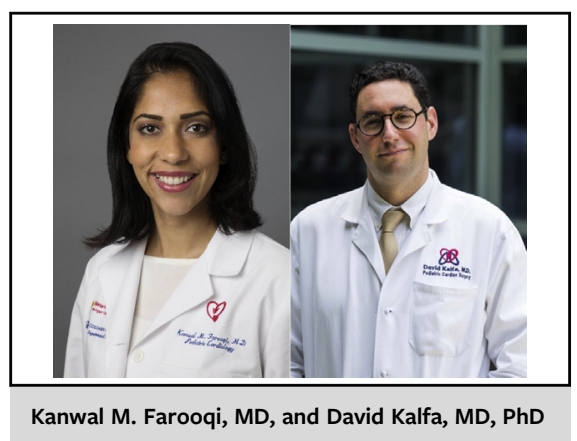

CENTRAL MESSAGE

Virtual reality can be successfully

applied for surgical planning in

pediatric and congenital cardiac

surgery and should be developed

in the centers than can invest in

this innovative technology.

atrioventricular valve annulus, interfering with its function. These subtle anatomic insights are challenging to fully embrace from cross-sectional imaging, such as cardiac magnetic resonance imaging or computed tomography scans.

Given that the authors have highlighted the utility of this technology, one must consider the feasibility of adopting the technology in one's own center. This is not specifically addressed in this report. A good quality dataset from either magnetic resonance imaging or computed tomography is needed to perform a process known as segmentation to highlight the anatomic area of interest. Software to perform the segmentation, as well as personnel who are familiar with this process, are needed to create the digital reconstruction that is imported into the VR system. Cost is also associated with the computer and headset that allow the user to interact with the virtual environment. The applicability of this exciting and innovative technique for virtual fit of adult VADs in pediatric patients will be highly dependent on individual center VAD volume, as well as on the availability of funding to support such innovative and exciting endeavors.

Presurgical planning using VR also can be applied to many other procedures in our specialty, such as complex intracardiac biventricular repair. It will revolutionize the teaching and training for surgical residents and fellows. Finally, its main promise is certainly in intraoperative use during the actual procedure with the surgeon wearing a VR headset, allowing superposition of the VR image on the heart after sternotomy to virtually "cut" through the heart before actually doing it. The future is here. 


\section{References}

1. Davies RR, Hussain T, Tandon A. Using virtual reality simulated implantation for fit-testing pediatric patients for adult ventricular assist devices. J Thorac Cardiovasc Surg Tech. 2021;6:134-7.

2. Almond CS, Morales DL, Blackstone EH, Turrentine MW, Imamura M, Massicotte P, et al. Berlin Heart EXCOR pediatric ventricular assist device for bridge to heart transplantation in US children. Circulation. 2013;127: 1702-11.

3. Dipchand AI, Kirk R, Naftel DC, Pruitt E, Blume ED, Morrow R, et al. Ventricular assist device support as a bridge to transplantation in pediatric patients. J Am Coll Cardiol. 2018;72:402-15. 